\title{
DETERMINANTES PSICOSSOCIAIS DO CUIDADO DOMÉSTICO POR MEMBROS DE FAMÍLIAS DE PESSOAS QUE VIVEM COM HIV/AIDS*
}

\author{
PSYCHOSSOCIAL DETERMINANTS OF DOMESTIC CARE BY \\ FAMILIES'S MEMBERS OF PERSONS WHO LIVE WITH HIV/AIDS
}

Cíntia Yuri S. B. Machado', Marco Antonio de C. Figueiredo², Lícia B. de Souza ${ }^{3}$

\begin{abstract}
${ }^{1}$ Aluna do Curso de Graduação, ${ }^{2}$ Docente, ${ }^{3}$ Psicóloga. Departamento de Psicologia e Educação. Faculdade de Filosofia, Ciências e Letras de Ribeirão Preto - USP.

CoRResPondÊnCIA: Marco Antonio de C. Figueiredo. Faculdade de Filosofia, Ciências e Letras de Ribeirão Preto - USP, Departamento de Psicologia e Educação. Avenida dos Bandeirantes, n 3900, Bairro Monte Alegre, Ribeirão Preto, São Paulo, Brasil. CEP: $14040-901$. e-mail: macfigueiredo@ffclrp.usp.br
\end{abstract}

Machado CYSB, Figueiredo MAC, Souza LB. Determinantes psicossociais do cuidado doméstico por membros de famílias de pessoas que vivem com HIV/aids. Medicina (Ribeirão Preto) 2008; 41 (2): 153-61.

RESUMO: O investimento em formação e orientação de pessoas leigas envolvidas no cuidado em HIV/aids tem permitido a criação de recursos paralelos ao atendimento hospitalar. A família pode representar uma fonte de recursos para regular o fluxo da hospitalização e amenizar o convívio da pessoa com a doença e seus efeitos desagregadores, determinados por pré-concepções de gênero, sexualidade, uso de drogas e homossexualidade. Esta pesquisa teve como objetivo identificar, sob a perspectiva de cuidadoras domésticas, alguns elementos para a apropriação de condições efetivas para a manutenção do cuidado de pessoas com HIV/aids no ambiente doméstico. Foram realizadas entrevistas semi-estruturadas com 4 cuidadoras domésticas, acompanhantes de seus familiares com HIV/aids, no ambulatório da Unidade Especial de Tratamento a Doenças Infecto-Contagiosas do Hospital das Clínicas da Faculdade de Medicina de Ribeirão Preto - USP. As entrevistas seguiram os procedimentos de evocação, enunciação e verificação de respostas. Posteriormente, sucessivas análises de conteúdo sobre a transcrição das entrevistas, permitiram a síntese em Categorias e Subcategorias Temáticas. Os conteúdos relacionados à continência para as necessidades físicas e afetivas, características de papéis incorporados pela mulher na divisão de trabalho por gênero, e a busca de uma reciprocidade quanto à troca de afetos, envolvendo cuidador e pessoa cuidada, foram prevalentes na fala das participantes. Os resultados apontam para a necessidade de reintegração do equilíbrio psicoafetivo da mulher, enquanto cuidadora doméstica, num contexto determinado pela vulnerabilidade feminina e a naturalização dos papéis de gênero. (CNPq).

Descritores: HIV. Cuidadores. Família.

\section{1- INTRODUÇÃO}

Após 20 anos da descoberta do vírus da imunodeficiência adquirida (HIV) e do início da epidemia da aids que atingiu todo o mundo, diversos avanços rela- tivos ao tratamento, prevenção e políticas de saúde têm sido feitos. Nesse contexto, a Psicologia e suas áreas afins têm dado importantes contribuições como, por exemplo, no âmbito da prevenção de comportamentos de risco, na adesão ao tratamento farmacoló-

*Este trabalho foi financiado pelo CNPq. 
gico e nas terapias dirigidas a pacientes enfermos. Atualmente a aids tem se tornado um fenômeno multidimensional que afeta não somente a vida das pessoas soropositivas para o HIV, como também seus parceiros sexuais, familiares e profissionais da saúde.

Não existe, ainda, tratamento definitivo para a aids, mas a terapêutica anti-retroviral foi um progresso realizado desde o surgimento da doença, que permitiu prolongar e qualificar o convívio das pessoas doentes e seus familiares com as vicissitudes da aids. $V z^{1}$ reforça essa questão, quando afirma que a tecnologia hoje existente e disponibilizada para o tratamento das pessoas portadoras do HIV/aids aumenta o tempo e a qualidade de vida destas pessoas.

A sobrevida à infecção pelo HIV, dilatada pelo advento de drogas inibidoras da reprodução do vírus no organismo, atribuiu à infecção características de uma doença crônica, possibilitando uma crescente desospitalização dos pacientes e seu retorno aos serviços primários e secundários de saúde, envolvendo também uma maior participação das famílias e de outros cuidadores no tratamento e cuidado dos pacientes. Neste processo, a família voltou a ser considerada como uma importante fonte de recursos para regular o fluxo da hospitalização, amenizando o convívio da pessoa com a doença e seus efeitos desagregadores. Ao mesmo tempo, a família também passou a enfrentar determinados conflitos, desencadeados por pré-concepções de gênero ${ }^{2}$, vivência da sexualidade ${ }^{3}$, da drogadição $0^{4}$ e do homossexualidade . $^{5}$.

As reações da família e da pessoa com HIV/aids decorrem de percepções sobre a doença, sendo influenciadas por uma multiplicidade de significados construídos socialmente, sendo alguns estigmatizantes, e que podem interferir nas relações dentro e fora do grupo familiar. Koller ${ }^{6}$ ressalta que as atitudes da família podem estar relacionadas às suas crenças e valores, formados ao longo da existência.

Strawn ${ }^{7}$ destaca que os familiares podem apresentar reações imprevisíveis, diante do diagnóstico positivo para HIV em algum de seus pares, devido a inúmeros fatores intrinsecamente envolvidos, como a diferença da natureza do relacionamento entre diversos membros da família, envolvendo papéis sociais, hierarquia de mando ou relações de gênero.

Desta forma Strawn ${ }^{7}$ afirma que a família pode apresentar um papel relevante na criação de carências emocionais e sociais para o portador do HIV, ou na minimização de tais necessidades, que podem vir a contribuir para a qualidade de vida.
Considerando a complexidade do contexto familiar e sua importância para o enfrentamento do convívio com a pessoa com HIV/aids, Moralez ${ }^{8}$ discute alguns pressupostos básicos para o estudo das relações familiares no contexto da aids:

“1) Ter um membro da família com aids em casa, gera muitos conflitos no âmbito familiar e, conseqüentemente, se torna uma experiência angustiante. 2) A familia passa por grandes mudanças levando, muitas vezes, à desestruturação e isolamento social. Pode, ainda, ser segregada e até rejeitar o familiar doente.3) A potencialização das dificuldades financeiras $e$ a ausência de serviços públicos eficientes agravam as condições emocionais dos cuidadores domésticos. 4) A falta de informações suficientes para auxiliar a manutenção destes individuos em casa, com carinho e segurança." (p. 16)

A família então se configura como um lugar em que a questão da aids é suscitada e se torna objeto de percepção. Cada família movimenta-se de forma singular, interpretando a situação a partir de sua cultura, seus códigos e suas regras, que irão influenciar o comportamento e o processo de comunicação entre seus membros.

Martin e Baldessim ${ }^{9}$ afirmam que o impacto da descoberta do diagnóstico positivo para o HIV ou a descoberta da aids em um membro de qualquer família faz emergir sentimentos que são expressos nas mais variadas formas de reações. Sentimentos como vergonha, culpa, raiva, negação, rejeição, indiferença, acolhimento, compreensão, apoio e aceitação se mesclam, envolvendo a pessoa com HIV/aids num contexto de incertezas sobre o que seus familiares pensariam a respeito de si e que tipo de sentimentos nutririam por ela.

O cuidado doméstico, na perspectiva de um processo que extrapola as atividades instrumentais da rotina diária no ambiente doméstico, visa suprir, além do suporte ao tratamento clínico, as necessidades das pessoas que vivem com HIV/aids relacionadas ao convívio com o contágio.

Assim, o investimento em formação e orientação de pessoas leigas envolvidas no cuidado em HIV/ aids tem possibilitado a criação de recursos paralelos ao atendimento dos serviços de saúde, e constitui uma alternativa importante para o trabalho que vem sendo realizado por equipes profissionais nestes serviços.

De acordo com trabalhos anteriores ${ }^{10,11}$, foi possível verificar a carência de informação por pes- 
soas pertencentes a estratos menos favorecidos da população que contribui, no âmbito da saúde ${ }^{12}$, para afirmar a vulnerabilidade feminina ao contágio pelo HIV/aids, e naturalizar papéis de gênero exercidos pela mulher.

Como conseqüência de responsabilidades relacionadas à submissão da mulher aos papéis de gênero, o avanço da feminilização da epidemia de aids ${ }^{13}$ tem colocado em evidência um grande número de elementos que potencializam uma predisposição feminina às Doenças Sexualmente Transmissíveis (DST) ${ }^{14,15}$, pauperização ${ }^{2,16}$, desemprego ${ }^{17,18}$, exploração ${ }^{19}$, drogadição ${ }^{10,20}$ e violência domiciliar ${ }^{21}$, que a inscreve em um processo de vulnerabilização social ${ }^{11,22}$ e de vitimização no contexto da saúde.

Este estudo buscou identificar alguns elementos da apropriação de condições efetivas, utilizados por cuidadoras domésticas, na manutenção do cuidado de pessoas com HIV/aids no ambiente doméstico, como informação, capacidade de acolhimento, vínculos afetivos, condições de cuidado, entre outros.

\section{2- METODOLOGIA}

Este estudo fez parte de um projeto de pesquisa integrado ao Programa de Atendimento Psicossocial à Aids ${ }^{23}$, cujas análises preliminares identificaram, na família do paciente, alguns elementos relevantes para tratar das necessidades relacionadas ao convívio com o HIV/aids.

Foi utilizada a abordagem teórica-metodológica das Representações Sociais ${ }^{24,26,27}$ como forma de aproximação dos conteúdos relacionados às vivências do cuidador doméstico nas relações que estabelece com seu familiar que vive com HIV/aids. A coleta de dados ocorreu entre novembro de 2005 e março de 2006.

\section{1- Participantes}

O projeto de pesquisa do qual este estudo derivou foi submetido e autorizado pelo Comitê de Ética em Pesquisa da Faculdade de Filosofia, Ciências e Letras de Ribeirão Preto - USP, e teve assegurado o anonimato dos participantes para a realização das entrevistas. Foram incluídos no estudo os familiares que compartilhavam o mesmo ambiente doméstico da pessoa cuidada e que aceitaram participar do estudo. Tal participação foi inteiramente voluntária e esteve de acordo com os termos de consentimento livre e esclarecido.

Foram entrevistadas quatro mulheres, cuidadoras de pessoas com HIV/aids, acompanhantes de pacientes do Ambulatório da Unidade Especial de Tratamento a Doenças Infecciosas (UETDI) do Hospital das Clínicas de Ribeirão Preto, da Universidade de São Paulo. Três cuidadoras entrevistadas eram solteiras, na faixa etária entre 15 e 17 anos, cursavam o ensino médio e ajudavam nos cuidados de suas mães. Uma cuidadora era casada, tinha 46 anos, ensino médio completo e acolheu o irmão em sua casa. Nenhuma destas mulheres exerciam atividades fora do lar.

\section{2- Procedimento}

O contato inicial com os participantes da pesquisa foi realizado na sala de espera do ambulatório da UETDI. As entrevistas foram realizadas individualmente, áudio-gravadas, com base em roteiro semiestruturado, agendadas de acordo com o consentimento e disponibilidade dos participantes, que escolheram ser entrevistas em suas residências. Inicialmente eram esclarecidos os objetivos do estudo e registradas as informações para caracterização dos participantes.

O levantamento de conteúdos sobre o tema "cuidado doméstico" seguiu o procedimento de livre enunciação que compreendeu as três etapas consecutivas:

a) Evocação: foi solicitado à pessoa entrevistada para que refletisse sobre o tema proposto, com o objetivo de identificar os conteúdos de crenças e representações.

b) Enunciação: a pessoa entrevistada discorreu sobre o que de mais importante pensou acerca do tema. $\mathrm{O}$ entrevistador transcreveu os conteúdos ipsis litteris.

c) Averiguação: na parte final, a entrevista foi desenvolvida a partir da verificação e complementação das informações pela pessoa entrevistada.

\section{3- Análise de conteúdo e tratamento dos dados}

As entrevistas foram transcritas e a análise de conteúdos foi realizada com base em procedimentos de inclusão em Subcategorias e Categorias Temáticas, definidas a posteriori ${ }^{27}$, de acordo com o seguinte procedimento a seguir:

a) Leitura inicial: foram realizadas leituras em profundidade para identificação de unidades te- 
máticas relacionadas ao tema abordado nas entrevistas;

b) Marcação e recorte: as unidades temáticas foram selecionadas e destacadas do corpus de análise;

c) Primeira junção: as unidades temáticas recortadas foram agrupadas por participante da pesquisa e organizadas em um protocolo;

d) Notação: foram feitas observações sobre cada uma das unidades temáticas, com o objetivo de identificar e interpretar os significados atribuídos pela pessoa entrevistada, tendo como referência informações da literatura da área;

e) Síntese: as notações serviram como referencial para a organização das unidades temáticas em uma segunda junção, em que foram agrupados os conteúdos de todas as entrevistadas em Subcategorias e Categorias Temáticas.

\section{3- RESULTADOS}

A análise de conteúdo permitiu identificar os principais pontos de referência das representações acerca da vivência das cuidadoras, que foram analisados a partir de Categorias derivadas de Categorias gerais dentro de um referencial teórico-metodológico que aborda processos históricos de construção de representações sobre saúde/doença na sociedade.

Na perspectiva das Cuidadoras Domésticas, as representações sobre suas vivências foram sintetizadas em Subcategorias e Categorias Temáticas subseqüentes:

a) Apropriação: identificação de necessidades existentes no cuidado doméstico e apoderamento de condições para supri-las por meio dos seguintes mecanismos:

- continência: acolhimento dispensado às necessidades físicas e afetivas por parte de quem cuida;

- reciprocidade: relação de troca de confiança e de cuidados prestados entre a pessoa que acolhe e a pessoa que é acolhida;

- trabalho doméstico: a cuidadora se apropria de tarefas domésticas, antes exercidas pela pessoa cuidada, para diminuir os encargos sob sua responsabilidade.

b) Contraponto (busca da normalidade): estabelecimento de um padrão de "normalidade" dado o grau de dificuldades encontradas na realização do cuidado.

c) Enfrentamento: manifestação de elementos determinantes para lidar com as vicissitudes dos aspectos desagregadores do HIV/aids:

- adesão: envolvimento com os cuidados clínicos no serviço de saúde que instrumentalizam a pessoa que acolhe para lidar com as dificuldades emergentes no cuidado doméstico;

- bloqueios psicológicos: dificuldades afetivas decorrentes do processo do cuidado doméstico frente às questões relacionadas à doença;

- condições do cuidado: situações determinantes do contexto doméstico sob as quais o cuidado se realiza;

- facilitadores: condições subsidiárias à administração do cuidado doméstico.

- papéis de gênero: responsabilidades relacionadas ao trabalho doméstico e que são naturalizadas e atribuídas à figura feminina;

- manutenção: busca de elementos para conservação e estabilidade de um quadro clínico sob controle;

- reintegração: busca do equilíbrio psicoafetivo para integridade emocional das partes envolvidas (quem cuida e quem é acolhido).

d) Naturalização do cuidado doméstico: representações sobre papéis femininos que facultam à mulher atribuições relacionadas ao cuidado doméstico.

\section{4- DISCUSSÃO}

A família, enquanto unidade de cuidado e de ajuda para a pessoa com HIV/aids, pauta suas atitudes em representações construídas ao longo da existência, que estão de acordo com a sua cultura, seus códigos e suas regras, que acabam influenciando comportamentos e o processo de comunicação entre os seus membros. Os conteúdos relacionados a "Ser cuidador" identificaram a busca de um Contraponto para se explicar a "Normalidade" do cuidado doméstico prestado a um familiar que vive com HIV/aids e que parecem estar fundamentados no grau de dependência da pessoa cuidada e na observação de experiências do meio social:

“ (...) a gente vê outras pessoas na rua, na televisão, que tem dificuldades em andar, em se 
movimentar. Minha mãe não, aqui com ela é tudo bem... a única dificuldade dela que tem é o remédio. (...) pensei, em primeiro lugar, que tem que pegar remédio, comida, tudo e levar pra ela. Aqui não, a minha mãe já pega tudo sozinha..." (Cuidadora 2).

No caso da Cuidadora 2 o contraponto se baseia em representações sobre o cuidado doméstico dirigido por outras pessoas a seus familiares com HIV/ aids, que se encontram, porém, em condições adversas, em oposição ao quadro assintomático de sua mãe, que não oferece maiores dificuldades para o cuidado.

Considerando o caráter imanente do convívio com o HIV/aids, o cuidado é vivido não apenas pelo membro da família que contrai a doença, como também por seus familiares, que são fonte de inquietações, dilemas éticos, ansiedades e conflitos. A posição da cuidadora na relação com a pessoa cuidada propicia a identificação de necessidades naturalizadas ao cuidado doméstico, que a impulsiona ao processo de Apropriação das condições necessárias para minimizar possíveis dificuldades. A cuidadora doméstica mobiliza recursos materiais e psicossociais para amenizar o convívio com a doença e atenuar seus efeitos desagregadores, sendo um deles o Acolhimento dispensado à pessoa cuidada:

"Porque, como ele fez durante os cinco primeiros anos que ele já sabia da doença, ele escondeu, né... Agüentou tudo sozinho. Fico agradecida por ele dividir comigo esse problema". (Cuidadora 1).

Neste relato, os elementos de apropriação parecem estar relacionados à capacidade de aceitação, baseados no reconhecimento da possibilidade de apoio e na propensão ao envolvimento com as necessidades do irmão.

Ainda nesse trecho, observa-se a existência de uma relação de Reciprocidade entre cuidador e pessoa cuidada, que envolve confiança nos cuidados administrados, fazendo com que a cuidadora se reconheça como competente:

"Eu me sinto agradecida pela oportunidade que meu irmão me deu, confiando em mim, né... É... Pelo fato de ele tá doente, né, e confiando que eu seja capaz de acompanhá-lo, né, durante essa doença" (Cuidadora 1).

A oportunidade de exercer o cuidado doméstico pareceu suprir uma necessidade de auto-realização, com conotações de nobreza, e da expressão de sentimentos relacionados à realização do cuidado, que envolve a confiança na própria capacidade pela pessoa que acolhe.

Da mesma forma, foi possível verificar que a apropriação por Reciprocidade pode envolver sentimentos de reconhecimento e de gratidão por parte da cuidadora:

"Olha eu me sinto bem (...) Tô fazendo a minha parte né? (...) porque ela cuidou de mim a vida inteira né. Agora chegou a minha vez de cuidar dela" (Cuidadora 2).

Nesse trecho, a fala sobre os sentimentos associados à possibilidade de cuidar da mãe, evidenciou a apropriação de conteúdos referentes à concepção de feminino como continente para as funções de cuidadora. Ainda apoiada na concepção de relações de gênero, pôde ser observado que o cuidador feminino tende a se apropriar de tarefas domésticas, outrora exercidas pela pessoa cuidada, com o intuito de minimizar o desgaste dos antigos encargos:

“Ah! eu cozinho, limpo a casa, faço comida. Aí eu tô indo pra escola e ela só faz janta mesmo. (...) Ajudo ela em tudo. (...) Ah! eu gosto de ajudar minha mãe... quando ela levanta assim eu já faço tudo né, aí eu faço almoço, depois que ela levanta, aí.. de noite ela só faz a janta, eu limpo tudo na casa, limpo tudo" (Cuidadora 4).

Nesta fala, há referências sobre a divisão de trabalho relacionada a gênero, em que são enunciadas tarefas diárias de limpeza e refeições interrompidas pela ida à escola, quando a cuidadora é substituída pela pessoa cuidada, no caso a mãe.

Representações de que o cuidado doméstico deve ser exercido pela mulher, parecem caracterizar o processo de Naturalização dos papéis femininos nas relações de gênero que legitimam a mulher enquanto cuidadora:

"Fico feliz, por ter a oportunidade de demonstrar o meu carinho por ele estando perto, né... Ajudando enquanto ele não pode preparar a própria comida, enquanto não pode se locomover sozinho. (...) É isso, eu agradeço muito assim... Porque ele podia muito bem continuar morando sozinho sem falar pra gente. Pelo telefone, ele longe, como é que eu ia saber, né, se ele tava bem ou não?" (Cuidadora 1).

A pessoa acolhida, considerada impossibilitada de realizar por si só as atividades da vida diária, tem suas necessidades supridas pela manifestação de condições de proximidade física com sua cuidadora, o que parece proporcionar perspectivas de manutenção de 
trocas afetivas. Nesse contexto, a possibilidade de que a pessoa cuidada possa um dia estar longe é vista de forma ansiogênica pelo cuidador, o que impediria a ajuda e o monitoramento do cuidado dispensado.

Entretanto, em um outro momento do seu depoimento, a entrevistada expressa sentimentos ambivalentes relacionados ao convívio de papéis de gênero, que se encontram polarizados entre os deveres conjugais e o cuidado do irmão:

"Existem dificuldades. Em princípio eu tive que ficar longe do meu marido e dos meus filhos, porque meu irmão morava em São Paulo. Sozinho, né. Então para acompanhá-lo eu tive que ir pra São Paulo, fiquei lá durante oito meses. (...)Teve dificuldades, porque eu sentia saudades demais... Ao mesmo tempo que eu queria tá com meu irmão cuidando dele, eu queria tá em casa cuidando do meu marido e dos meus filhos, né" (Cuidadora 1).

A entrevistada menciona, também, conquistas ligadas à redução de ambivalência pela resolução dos problemas gerados pela distância:

"Mas eles sabiam que eu tava em São Paulo esperando passar a crise mais séria que meu irmão tava vivendo, né, até poder trazê-lo pra Ribeirão Preto. Conseguiu aposentadoria, trazendo pra perto da gente" (Cuidadora 1).

Baseado em manifestações sobre elementos de justificativa para a dubiedade de responsabilidades e redução de dissonância originada por papéis de gênero, a cuidadora se apropria de recursos para o Enfrentamento, considerando os limites das Condições do Cuidado Doméstico.

A questão de Papéis de Gênero, envolvendo responsabilidades relacionadas à vida conjugal, à criação dos filhos e ao cuidado doméstico ao irmão, é retomada quando ambos retornam ao lar da família da cuidadora, iniciando um processo de conciliação de responsabilidades:

"Eu tenho que... Tá sempre atenta, porque, junto com o... o sofrimento do meu irmão tenho também as minhas dificuldades como ser humano, né. As minhas inseguranças, né, os... os filhos tão aí moços, né. Eu tenho preocupações, com... os horários, os filhos saírem e voltar pra casa, se tá indo tudo bem no trabalho, se não tá" (Cuidadora 1).

Embora o papel da mulher na sociedade venha sofrendo transformações nas últimas décadas, as re- lações de gênero, legitimadas pela organização patriarcal da família, freqüentemente relegam à mulher uma posição de submissão ao homem, principalmente no espaço privado e no papel de cuidar. O processo de feminilização da epidemia do HIV/aids encontra nestas relações seus determinantes, que submetem a mulher a uma série de elementos da vulnerabilidade para o contágio. De acordo com Santos ${ }^{18}$ as mulheres têm menor autonomia para discutirem questões afetas à sexualidade, diretamente ligadas à prevenção de DST e aids.

Retomando as considerações sobre a importância dos papéis desempenhados pela família para atenuar carências emocionais e sociais apresentadas pelo portador do HIV, pode ser observada a emergência do processo de Enfrentamento enquanto elemento para administrar as vicissitudes relacionadas aos aspectos desagregadores do convívio com HIV/aids. Nesse sentido, foram identificados conteúdos associados às condições Facilitadoras, subsidiárias à administração do cuidado doméstico:

"Quando tá bem, muito bem... ele conversa muito. Faz brincadeiras sobre as dificuldades que ele tem, porque não pode mexer a mão, ou a mão fica tendo as convulsões, fica pulando... Ele ainda faz piadas, né..." (Cuidadora 1).

Por outro lado, Bloqueios Psicológicos, determinados por dificuldades afetivas, refletem no manejo das questões relacionadas à doença:

"Uma dificuldade também é quando meu irmão tá mais doente, com muita febre, com muito mal estar. Fica muito sensivel. A gente tem que ter muito cuidado... com qualquer coisa que fale com ele. Ele não... quer que fale da doença, né. Fica procurando meios de não encarar, né, uma doença, porque é diferente. Então ... é difícil a gente conversar quando ele não tá bem... Quando ele tá assim... muito fragilizado, é difícil ver o sofrimento dele" (Cuidadora 1).

A dificuldade de distanciamento do sofrimento do outro durante o cuidado parece dificultar a administração das questões relacionadas à doença. Entretanto, ocorre um movimento de busca de superação de bloqueios afetivos relacionados ao sofrimento, originados pelo cuidado, como elementos de enfrentamento para a manutenção da integridade psicológica da pessoa cuidada, numa tentativa de Reintegração: 
"Então, além de todas as preocupações naturais que qualquer pessoa tem, ainda tenho que tá bem e bem disposta pra ver... Vivenciar esse sofrimento físico do meu irmão e... com... com uma certa alegria, né, porque ele não pode ficar triste, ver que eu fico triste sabendo como é que ele tá passando, né. Então eu tenho que me fortalecer, né, pra poder cuidar dele também" (Cuidadora 1).

A procura por um equilíbrio psicoafetivo que visa amenizar a dissonância entre diferentes estados emocionais, imanentes ao relacionamento, também é verificada na fala de outra cuidadora:

“(...) você não tem aquela preocupação, você fica mais aliviada né... (...) Ah porque não tem aquela preocupação né. (...) De, assim, de eu não ter cuidado dela e mais cedo e mais tarde ficar, sabe, naquele remorso que... eu penso assim, ah, eu tô fazendo minha parte então não vai acontecer nada... porque é que nem eu falei né. Você se sente mais aliviada, fica mais tranqüila. Eu não tenho, assim... preocupação" (Cuidadora 2).

A ambivalência de sentimentos estabelece um contraponto à gratidão enunciada com relação ao cuidado que a mãe prestou à pessoa entrevistada, enquanto manifestação de alívio, com uma conotação de "desencargo de consciência" por poder retribuí-la com o exercício do cuidado doméstico.

Enquanto parte dos processos de enfrentamento, o suporte doméstico para a Adesão ao cuidado especializado mostra a importância do suporte doméstico aos cuidados dos profissionais de saúde nos serviços:

"Todo mês né eu vou com minha mãe. (...) Acompanho ela no médico. Ela me chama pra ir com ela, eu vou. (...) Todo mês eu vou. (...) Ela vai sempre, ela não falta. (...) Ela vai todo mês, ela não falta... ela vai, tira sangue, ai dá uma semana ela vai no médico" (Cuidadora 3).

A adesão ao tratamento parece se sustentar pela representação de que o atendimento especializado auxilia na manutenção e estabilidade do quadro clínico:

"Ah! Eu não quero que minha mãe fique doente. (...) Eu quero que ela melhora logo, ficasse... ficasse boa logo... não voltasse a ficar doente de novo... ela... ficasse boa logo.Por isso que eu vou todo mês com ela. (...) Ah! Eu não queria que minha mãe ficasse doente né. Deu derrame nela. Eu não queria que minha mãe ficasse doen- te. (...) Jááá... tá boa... andando normal. (...) Faz três anos já" (Cuidadora 3).

Esse é um depoimento com ênfases perseverantes sobre a manutenção e estabilidade do quadro clínico da pessoa cuidada com indicadores de angústia antecipatória relacionada a reincidivas de afecções enfrentadas no passado.

\section{5- CONSIDERAÇÕES FINAIS}

O advento da aids no interior da família é um acontecimento marcante e foco de novas direções, pois determina o fim de um modo de vida, iniciando-se uma outra forma de viver da família, como se fosse um rito de passagem.

Embora sintam o impacto das vicissitudes e das necessidades provenientes do adoecimento pelo HIV/ aids de forma semelhante, tanto a família, quanto o membro que adoece, buscam elementos para o enfrentamento de maneira peculiar. A família, mergulhada em contradições e desencontros, que trazem à tona ressentimentos, impotência e tristeza, se apropria de meios que visam amenizar as dificuldades emergentes, bem como o acolhimento da pessoa que vive com o HIV/aids. Esse papel de cuidador é desempenhado, sobretudo, pela mulher que, submetida às responsabilidades das relações de gênero, encontra-se numa posição subordinada em relação ao homem, sendo-lhe incumbidas tarefas relacionadas à continência para as necessidades físicas e afetivas. $\mathrm{O}$ cuidado doméstico passa a constituir uma dupla jornada, em que a mulher acumula encargos, inscritos em uma lógica especializada, referentes às questões técnicas da manutenção de uma pessoa doente em casa.

Essa duplicidade de encargos re-significa seus papéis, determinando a busca de recursos para o enfrentamento de sua nova condição e aponta para a necessidade de reintegração do equilíbrio psicoafetivo da mulher cuidadora, num contexto determinado pela vulnerabilidade feminina e a naturalização dos papéis de gênero.

Assim, o presente estudo possibilitou uma maior compreensão sobre o impacto do adoecimento por HIV/aids no ambiente familiar, que é influenciado tanto pela história construída no seu interior quanto na convivência social. Dessa forma, a família cria significações em relação ao seu integrante portador do HIV/aids e em relação a si mesma, buscando encontrar recursos para enfrentar sua nova condição. 
Machado CYSB, Figueiredo MAC, Souza LB. Psychossocial determinants of domestic care by families's members of persons who live with HIV/aids. Medicina (Ribeirão Preto) 2008; 41 (2): 153-61.

ABSTRACT: The investment in training and counselling of laypeople involved in the care in HIV/ aids has allowed the creation of parallel resources to the hospital attendance. The family can represent a source of resources to regulate hospitalization flow and to reduce the amount of time spent coping with the disease and its desruptive effects, determined by preconceptions of gender, sexuality, use of drugs and homosexuality. This research aimed at identifying, under the perspective of domestic caregivers, some elements of appropriation of effetive conditions for the maintenance of care of people with HIV/aids in the domestic environment. Half-structuralized interviews were carried with 4 domestic caregivers, their relatives with HIV/aids companions, in the clinic of the Special Unit of Treatment the Infectum-Contagious IIInesses from the Clinics Hospital of the Faculty of Medicine of Ribeirão Preto. The interviews had followed the procedures of evocation, articulation and verification of answers. Later, successive analyses of content, on the transcription of the interviews, had allowed the synthesis in Thematic Categories and Subcategories. The contents related the containing for physical and affective needs, characteristic of the roles incorporated by the woman in the division of work for gender, and the search of a reciprocity related to affection exchange, involving the caregiver and the cared person, were prevalent in the speech of the participants. The results point to the necessity of reintegration of the psychoafective balance of the woman, as domestic caregiver, in a context determined for the feminine vulnerability and the naturalization of the rules of gender.

Keywords: HIV. Caregivers. Family.

\section{REFERÊNCIAS}

1 - Cezar-Vaz MR, Martins, SR, Rubira, LT, Santos, LR; Irala, DA; Moraes, TO. A certeza incerta da morte e suas metáforas na situação de acometimento de aids-tuberculose. Texto e Contexto.Enferm, (Florianópolis) 2001;10(3): 82-100.

2 - Suligoi B. The natural history of human immunodeficiency virus infection among women as compared with men. Sex Transm Dis 1997; 24(2): 77-83.

3 - Birman J. A sexualidade entre o mal e as maledicências. In: Loyola MA, org. Aids e sexualidade. O ponto de vista das ciências humanas. Dumará (RJ): Relume; 1994. p. 109-15.

4 - Mesquita, FC. Aids e drogas injetáveis. In: Lancetti, A, org. Saúde e Loucura 3. São Paulo: Hucitec; 1991. p. 47-53.

5 - Guimarães CD, Terto Jr,V, Parker R. Homossexualidade, bissexualidade e HIV/aids no Brasil: uma bibliografia anotada das ciências sociais e afins. Physis (Rio de Janeiro) 1992; 2(1): $151-83$.

6 - Koller EMP. Cuidando de famílias sob o impacto do vírus HIV em seu espaço sociocultural. [Dissertação de Mestrado], Florianópolis: Centro de Ciências da Saúde - UFSC; 1992.

7 - Strawn JM. As conseqüências psicossociais da aids. In: Durhan JD, Cohen FL, org. A Enfermagem e o aidético. São Paulo: Manole; 1989. p. 126-49.

8 - Moralez FR. Cuidadores de pacientes com aids na Unidade Leito-Dia do Hospital de Clínicas da UNICAMP: um estudo qualitativo de atos assistenciais e aspectos psicológicos envolvidos. [Tese de Doutorado], Campinas:Faculdade de Ciências Médicas - UNICAMP, 1997.
9 - Martin LM, Baldessin A. Conviver com a aids: subsídios para o doente, sua família e grupos de apoio. Aparecida (SP): Santuário; 1990.

10 - Franco FG, Figueiredo MAC. Aids, drogas e "ser mulher": relatos de mulheres soropositivas para o HIV. Medicina, (Ribeirão Preto), 2004; 37(1/2): 106-16.

11 - Saldanha AAW, Figueiredo MAC. Vulnerabilidade e construções de enfrentamento da soropositividade ao HIV por muIheres infectadas em relacionamento estável. In: SIDAnet, Associação Lusófona, org.. A mulher e a infecção pelo HIV/ SIDA. (Portugal) Normagraf Santarém: Santarem; 2004. 1: 49-58.

12 - Figueiredo MAC, Bossa AC. Grupo de acompanhantes da pediatria - Unidade Especial de Tratamento de Doenças Infecciosas - U.E.T.D.I. Serv Soc - Hospital das Clínicas (FMRPUSP), Ribeirão Preto 2002; 2(2): 22-5.

13 - Porto CSBM. Gravidez e infecção pelo HIV. Buscando a ótica feminina na produção da saúde. [Anais] I Fórum e II Conferência de Cooperação Técnica Horizontal da América Latina e do Caribe em HIVIAids e DST. Rio de Janeiro; 2000; 839.

14 - Ribeiro DF. A devolução do diagnóstico soropositivo do exame anti-HIV e o ponto de vista da pessoa infectada. [Monografia de Bacharelado]; Ribeirão Preto: Faculdade de Filosofia, Ciências e Letras de Ribeirão Preto - USP; 1996.

15 - Parker R. A construção da solidariedade. Aids, sexualidade e política no Brasil. Rio de Janeiro: ABIA, Relume-Dumará; 1994.

16 - Parker R, Camargo Jr, KR. Pobreza e HIV/aids: aspectos antropológicos e sociológicos. Cad Saúde Pública 2000; 16 (Supl. 1): 89-102. 
17 - Parker R, Aggleton P. Estigma, discriminação e aids. Rio de Janeiro: ABIA; 2001. p.9-12 . [Coleção ABIA: Cidadania e Direitos, 1]

18 - Santos NJS. Características sociais, risco e ocupação nas mulheres com aids em São Paulo. São Paulo(Estado). Secretaria de Estado da Saúde; jun.1998.p.39-53 (Atualidades em DSTs/Aids, 2).

19 - Ferreira RCM, Figueiredo MAC. Aids e desemprego. Um estudo sobre o convívio com HIV/aids e as dificuldades com o mercado de trabalho. [Monografia de Bacharelado], Ribeirão Preto: Faculdade de Filosofia, Ciências e Letras de Ribeirão Preto - USP; 2004.

20 - Caiaffa WT, Bastos FI. Usuários de drogas injetáveis e infecção pelo vírus da imunodeficiência humana: epidemiologia e perspectivas de intervenção. Rev. Bras. Epidemiol 1998; 1(2): 190-202.

21 - Lippimann SB, Jamer W, Frierson RL. Aids and the family. Implications for counselling. Aids Care 1993; 5 (1): 71-8.

22 - Figueiredo MAC. A program of psichosocial aids care for the community of HIV carriers and persons with aids in Ribeirão Preto, Brazil. Proccedings of the XII International Aids Conference. Social Science, rights, politics, commitment and action. Bologna: Monduzzi; 2000. p.461-5.
23 - Figueiredo MAC. Avaliação de um programa de orientação e suporte psicossocial do cuidado doméstico de pessoas que vivem com HIV/Aids: um estudo com base na perspectiva da tríade paciente/profissional/familiar. [Projeto de Pesquisa], Conselho Nacional de Desenvolvimento Científico e Tecnológico (CNPQ); 2004-2007.

24 - Jovchelovitch S. Representações sociais e esfera pública: a construção simbólica dos espaços públicos no Brasil. Petrópolis (RJ): Vozes; 2000.

25 - Cardoso MHCA, Gomes R. Representações sociais e história: referenciais teórico-metodológicos para o campo da saúde coletiva. Cad Saúde Pública 2000; 16 (2) 499-506.

26 - Minayo MCS. O desafio do conhecimento: pesquisa qualitativa em saúde. Säo Paulo: Hucitec; 1993.

27 - Figueiredo MAC. Escalas afetivos-cognitivas de atitude. Construção, validação e interpretação dos resultados. In: Romanelli, G; Biasoli-Alves, ZMM., org.Diálogos metodológicos sobre prática de pesquisa. Ribeirão Preto: Legis Summa; 1998. p. 51-70.

Recebido para publicação em 27/07/2007.

Aprovado para publicação em 05/03/2008. 